\title{
Antimicrobial and Cytotoxic Activities of Endophytic Fungi Isolated from Mangrove Plant Sonneratia alba Sm
}

\author{
Dian Handayani ${ }^{\prime *}$, Harrizul Rivai ${ }^{1}$, Rizka Mulyana $^{2}$, Netty Suharti $^{1}$, Roslaili Rasyid ${ }^{3}$, Triana Hertiani ${ }^{4}$ \\ ${ }^{1}$ Faculty of Pharmacy, Andalas University, Padang 25163, Indonesia. \\ ${ }^{2}$ School of Pharmacy, Padang, Indonesia. \\ ${ }^{3}$ Faculty of Medicine, Andalas University, Padang 25163, Indonesia. \\ ${ }^{4}$ Faculty of Pharmacy, Gadjah Mada University, Sekip Utara, Yogyakarta, Indonesia.
}

\section{ARTICLE INFO \\ Article history: \\ Received on: 17/09/2017 \\ Accepted on: 12/12/2017 \\ Available online: 27/02/2018}

\section{Key words: \\ Endophytic fungi, man- grove, Sonneratia alba $\mathrm{Sm}$, antimicrobial activity, cyto- toxic activity, Trichoderma koningiopsis, Aspergillus sydowii, Trichoderma lixii.}

ABSTRACT
Endophytic fungi are those that grow intra- or intercellular within the tissues of higher plants without causing a disease.
This study aims to evaluated antimicrobial and cytotoxic activities of endophytic fungi from leaf, bark and root of
mangrove Sonneratia alba $\mathrm{Sm}$, collected from Bungus, West Sumatra, Indonesia. The isolation of endophytic fungi
was done by using direct planting method with sabouraud dextrose agar (SDA) as growth medium. Thirteen isolates
fungi strains were obtained from this mangrove. They were cultivated on unpolished rice as medium for \pm 4 weeks,
and extracted with ethyl acetate. The ethyl acetate extracts were analyzed for antimicrobial and cytotoxic activities
by using agar diffusion method and MTT assay on T47D and Vero cells. The study revealed nine (69\%) of the total
extract had antimicrobial activity against pathogenic bacteria and fungal such as, Staphylococcus aureus, Escherichia
coli and Candida albicans. While nine extracts (69\%) were cytotoxic (Percentage of cell viability $<50$ ) against T47D
cells. Based on the results of antibacterial activity screening, three fungal isolates were selected as the most active
against $S$. aureus, E. coli and C. albicans. This selected fungal isolates were first macroscopically and microscopically
characterized and later molecularly identified as Trichoderma koningiopsis, Aspergillus sydowii and Trichoderma lixii
respectively. This study concluded that the endophytic fungi of Sonneratia alba Sm can be developed as a new source
of antibiotic and anticancer compounds.

\section{INTRODUCTION}

Terrestrial endophytic fungi found on leaves, stems, and roots of mangrove were more numerous than marine fungi (Latha and Mitra 1998). The endophytic fungi are known as a source of abundant secondary metabolites. Many endophytic fungi produce secondary metabolites which are very attractive in terms of their activity and chemical structure. The secondary metabolite such as alkaloids, phenolic derivatives, terpenoids and steroids plays an important role as a potential candidate of drug compounds, and useful in agro-chemical industries (Strobel and Daisy, 2003; Alfaro and Boyman, 2011).

Research on secondary metabolites produced by endophytic fungi from mangroves as a drug-producing compound has been

"Corresponding Author

Dian Handayani, Faculty of Pharmacy, Andalas University,

Padang, Indonesia.E-mail:dianh_17@yahoo.com widely performed. In continuation of our work on natural substances of terrestrial and marine origins (Handayani and Artasasta, 2017; Handayani and Aminah, 2017; Handayani et al., 2016, Handayani et al., 2015), we examined the endophytic fungi from the mangrove $S$. griffithi Kurz in producing antibacterial compounds (Handayani et al., 2017). Based on these potentials, continuous research on screening for antimicrobial and cytotoxic activities of other Sonneratia species, such as $S$. alba $\mathrm{Sm}$ has been performed. Screenings of antimicrobial and cytotoxic activities were performed on fungal extract isolated from leaves, bark, and roots of $S$. alba Sm collected from West Sumatra, Indonesia.

\section{MATERIAL AND METHODS}

\section{Material}

To isolate the endophytic fungi, fresh leaves, barks, and roots of $S$. alba Sm were collected from Nirwana Beach, West 
Sumatra, Indonesia. Samples of leaves, bark, and roots were taken as much as \pm 100 grams and then put in a clean and sterile plastic container and transported to the laboratory.

\section{Isolation, cultivation, and extraction of secondary metabo- lites from of endophytic fungi}

The research method for the isolation and cultivation of endophytic fungi have been carried out as written in the research that we have done before (Kjer et al., 2010; Handayani et al., 2017).

\section{Screening for antimicrobial activity}

Screening of antimicrobial activity of the EtOAc extracts of endophytic fungi was performed by the disk diffusion method (Bauer et al., 1966). The testing was done against pathogenic bacterial and fungal such as Staphylococcus aureus, Escherichia coli, and Candida albicans. The EtOAc extract was prepared to the concentration (in DMSO) 5, 3 and $1 \mathrm{mg} / \mathrm{ml}$. Tetracycline $\mathrm{HCl}$ and Ketoconazole as a reference compound were prepared at $300 \mu \mathrm{g} / \mathrm{ml}$ and $20 \mu \mathrm{mg} / \mathrm{ml}$ in distilled water, respectively. Each $10 \mu \mathrm{l}$ of above reference and extracts were dropped onto $6 \mathrm{~mm}$ sterile paper disk on the surface of the medium containing bacteria and fungi test strain. Each plate was incubated at $37^{\circ} \mathrm{C}$ for 24 hours for bacteria and at a temperature of $25^{\circ} \mathrm{C}-27^{\circ} \mathrm{C}$ for 5-7 days for fungi. Inhibition zones were measured and recorded. Screening of antibacterial activity was experimented in triplicate, and mean value \pm standard deviation was also determined.

\section{Screening for cytotoxic activity}

The cell line of T47D (human ductal breast epithelial tumor) and Vero (normal cell) have been prepared for cytotoxic assay using MTT. All cell lines were obtained from Laboratory of Parasitology at UGM. T47D was cultured in RPMI 1650 and Vero was cultured in M199 Medium. All cells were subcultured after mild trypsinization with trypsin-EDTA (Sigma-Aldrich, USA), and then determined the cell number and viability. The cells were seeds in 96-well plates at density 6x103 cells/well in $100 \mu \mathrm{l}$ medium and incubated overnight. All media were supplemented with $10 \%$ with fetal bovine serum (Gibco) and streptomycin and penicillin (2\%, Sigma-Aldrich, USA). The cell line was kept at $37^{\circ} \mathrm{C}, 98 \%$ relative humidity with $5 \% \mathrm{CO}_{2}$ atmosphere.

A stock solution was prepared by dissolving the samples in DMSO and was given 100.000 ppm concentration. Cells that had been incubated 24 hours, then divided into several groups, namely treatment, positive control, cell control and media control (blank). Removed medium and washed using PBS sterile which each well was added $100 \mu \mathrm{l}$ PBS. Then, $100 \mu \mathrm{l}$ of each material (extract) added to each well with one concentration (100 ppm). As control positive was used with doxorubicin. Then it was incubated for 24 hours in an incubator at $37^{\circ} \mathrm{C}, 5 \% \mathrm{CO}_{2}$.

Cells that had been treated and incubated 24 hours later dumped throughout the medium and washed using sterile PBS. Then in each well was added $100 \mathrm{~mL}$ of MTT $(5 \mathrm{mg} / \mathrm{ml})$ followed by 4 -hour incubation in an incubator at $37^{\circ} \mathrm{C}, 5 \%$ $\mathrm{CO}_{2}$. To each well was added $100 \mu$ l of $10 \%$ SDS to dissolve the formazan crystals formed and incubated one night at room temperature. The plates were then read by ELISA reader at 540 nm (Permanasari et al., 2016).

$\%$ Cell viability then was calculated by the equation

$$
\frac{\text { OD of treatmnet }- \text { OD of blank }}{\text { OD of control }- \text { OD of blank }} \times 100 \%
$$

The aim of this screening was to identify which sample was given cytotoxic activity in the cell line.

\section{Identification of fungal cultures}

Three endophytic fungal strains (SaKB1, SaAK3, and SaKB4) which have the greatest antibacterial activity were identified according to the molecular biological protocol with DNA amplification and sequencing of the ITS region (White, Bruns, and Lee 1990). The sequence data were submitted to GenBank. By comparing molecular sequences in National Center for Biotechnology Information. The fungal strains were kept in one of the author's labs (D.H.).

\section{RESULTS AND DISCUSSION}

\section{Antibacterial activity of fungal extracts}

In this study, thirteen endophytic fungal from leaves, roots, and bark of $S$. alba have been isolated. Observation of the fungus colony was done macroscopically (visual) based on color, surface, and the edge of the colony. The same criteria are considered to be the same isolates, and the criteria showing differences are considered to be different isolates. Each fungus isolate was then cultivated in rice medium for 30 days and extraction using ethyl acetate, with the aim of obtaining more secondary metabolites. The screening of antibacterial activity of this extract against $S$. aureus, E. coli, and $C$. albicans has been performed. Based on the screening results, it is known that seven endophytic fungal extracts (at concentration $5 \%$ ) can inhibit the growth of bacteria $E$. coli with a diameter of $>$ $10 \mathrm{~mm}$, nine extracts had inhibition against $S$. aureus and two extracts were active against $C$. albicans. The extract of SaKB1 had an average of the highest diameter of growth inhibitory against $S$. aureus (diameter inhibitory of $22.83 \mathrm{~mm}$ ), while the extract of SaAK3 and SaKB4 had the highest inhibitory effects on the growth of E. coli and $C$. albicans with diameter inhibitory of 15.33 and $14.57 \mathrm{~mm}$, respectively (Table 1).

\section{Cytotoxic activity of fungal extracts}

The cytotoxic activity screening of all extracts on T47D and Vero cell lines was evaluated as presented in Figure 1. The results revealed that $9(69.2 \%)$ out of 13 extracts tested were cytotoxic and exhibited a percentage of viability cell value $\leq 50 \%$. Of these, 6 extracts $(46.1 \%)$ from all extracts were found to have a percentage of viability cell value $\leq 20 \%$. Fungi extract with the lowest percentage of viability $(\leq 50 \%)$ especially against the T47D cancer cells are extracted SaDa1, $\mathrm{SaDa}$, SaDa3, SaDa5, SaDa6 and SaKB3 (Figure 1). The percentage of viability extracts against T47D cancer cells is highly variable and some of which are not toxic to the normal cells (Vero). 
Table 1: Antimicrobial activity of endophytic fungi extracts isolated from mangrove S. alba SM.

\begin{tabular}{|c|c|c|c|c|c|}
\hline \multirow[t]{2}{*}{ No } & \multirow{2}{*}{ Sample Code } & \multirow{2}{*}{ Concentrations } & \multicolumn{3}{|c|}{$\begin{array}{c}\text { Zone of Inhibition }(\mathrm{mm}) \pm \text { Deviation } \\
\text { Standard (SD) }\end{array}$} \\
\hline & & & SA & EC & CA \\
\hline \multirow{3}{*}{1} & \multirow{3}{*}{ SaDal } & $1 \%$ & $6.10 \pm 0.01$ & $6.56 \pm 0$ & $7.58 \pm 0.01$ \\
\hline & & $3 \%$ & - & $6.60 \pm 0$ & $11.80 \pm 0.00$ \\
\hline & & $5 \%$ & $9.75 \pm 0.07$ & $8.53 \pm 0.03$ & $14.08 \pm 0.00$ \\
\hline \multirow{3}{*}{2} & \multirow{3}{*}{$\mathrm{SaDa} 2$} & $1 \%$ & $9.07 \pm 0.20$ & $9.90 \pm 0.14$ & - \\
\hline & & $3 \%$ & $11.58 \pm 0.11$ & $11.38 \pm 0.39$ & - \\
\hline & & $5 \%$ & $15.58 \pm 0.00$ & $10.82 \pm 0.01$ & - \\
\hline \multirow{3}{*}{3} & \multirow{3}{*}{$\mathrm{SaDa} 3$} & $1 \%$ & - & - & - \\
\hline & & $3 \%$ & - & - & - \\
\hline & & $5 \%$ & $8.35 \pm 0.00$ & $5.57 \pm 0.01$ & $6.62 \pm 0.00$ \\
\hline \multirow{3}{*}{4} & \multirow{3}{*}{$\mathrm{SaDa} 4$} & $1 \%$ & $7.88 \pm 1.67$ & $6.85 \pm 0.01$ & $7.55 \pm 0.00$ \\
\hline & & $3 \%$ & $6.86 \pm 0.04$ & $6.06 \pm 0.00$ & - \\
\hline & & $5 \%$ & - & - & - \\
\hline \multirow{3}{*}{5} & \multirow{3}{*}{$\mathrm{SaDa} 5$} & $1 \%$ & $7.58 \pm 0.10$ & - & - \\
\hline & & $3 \%$ & $5.17 \pm 0.00$ & - & - \\
\hline & & $5 \%$ & $14.15 \pm 0.00$ & $7.11 \pm 0.00$ & $7.10 \pm 0.00$ \\
\hline \multirow{3}{*}{6} & \multirow{3}{*}{ SaDa6 } & $1 \%$ & $12.06 \pm 0.00$ & $10.83 \pm 0.04$ & $6.10 \pm 0.00$ \\
\hline & & $3 \%$ & $12.82 \pm 0.01$ & $12.65 \pm 0.01$ & $6.10 \pm 0.00$ \\
\hline & & $5 \%$ & $11.96 \pm 0.14$ & $14.12 \pm 0.00$ & $8.05 \pm 0.00$ \\
\hline \multirow{3}{*}{7} & \multirow{3}{*}{$\mathrm{SaDa} 7$} & $1 \%$ & $13.915 \pm 0.01$ & $8.45 \pm 0.00$ & - \\
\hline & & $3 \%$ & $15.60 \pm 0.00$ & $14.85 \pm 0.00$ & $8.86 \pm 0.00$ \\
\hline & & $5 \%$ & $22.83 \pm 0.00$ & $13.82 \pm 0.01$ & $11.8 \pm 0.00$ \\
\hline \multirow{3}{*}{8} & \multirow{3}{*}{ SaKB2 } & $1 \%$ & - & - & - \\
\hline & & $3 \%$ & $6.64 \pm 0.01$ & $7.50 \pm 0.00$ & - \\
\hline & & $5 \%$ & $10.08 \pm 0.00$ & $9.95 \pm 0.01$ & - \\
\hline \multirow{3}{*}{9} & \multirow{3}{*}{ SaKB3 } & $1 \%$ & $7.70 \pm 0.00$ & - & - \\
\hline & & $3 \%$ & $8.67 \pm 0.01$ & $8.17 \pm 0.00$ & $7.81 \pm 0.34$ \\
\hline & & $5 \%$ & $13.57 \pm 0.00$ & $13.15 \pm 0.00$ & $7.81 \pm 0.35$ \\
\hline \multirow{3}{*}{10} & \multirow{3}{*}{ SaKB4 } & $1 \%$ & $11.07 \pm 0.00$ & $11.00 \pm 0.00$ & $10.10 \pm 0.00$ \\
\hline & & $3 \%$ & $11.68 \pm 0.01$ & $11.57 \pm 0.02$ & $14.15 \pm 0.00$ \\
\hline & & $5 \%$ & $14.37 \pm 0.01$ & $13.65 \pm 0.00$ & $14.57 \pm 0.00$ \\
\hline \multirow{3}{*}{11} & \multirow{3}{*}{ SaAK1 } & $1 \%$ & $9.24 \pm 0.01$ & $9.13 \pm 0.04$ & - \\
\hline & & $3 \%$ & $10.53 \pm 0.01$ & $10.20 \pm 0.00$ & $6.81 \pm 0.01$ \\
\hline & & $5 \%$ & $14.37 \pm 0.00$ & $15.15 \pm 0.00$ & $6.83 \pm 0.01$ \\
\hline & & $1 \%$ & - & - & - \\
\hline 12 & $\mathrm{SaAK} 2$ & $3 \%$ & - & $8.05 \pm 0.00$ & $7.75 \pm 0.00$ \\
\hline & & $5 \%$ & $9.86 \pm 0.01$ & $9.33 \pm 0.04$ & - \\
\hline & & $1 \%$ & $9.08 \pm 0.00$ & $9.15 \pm 0.00$ & - \\
\hline 13 & $\mathrm{SaAK} 3$ & $3 \%$ & $9.84 \pm 0.01$ & $11.10 \pm 0.00$ & $7.10 \pm 0.00$ \\
\hline & & $5 \%$ & $11.80 \pm 0.01$ & $15.33 \pm 0.00$ & $9.60 \pm 0.00$ \\
\hline
\end{tabular}

SA: Staphylococcus aureus, EC: Escherichia coli, CA: Candida albicans. 


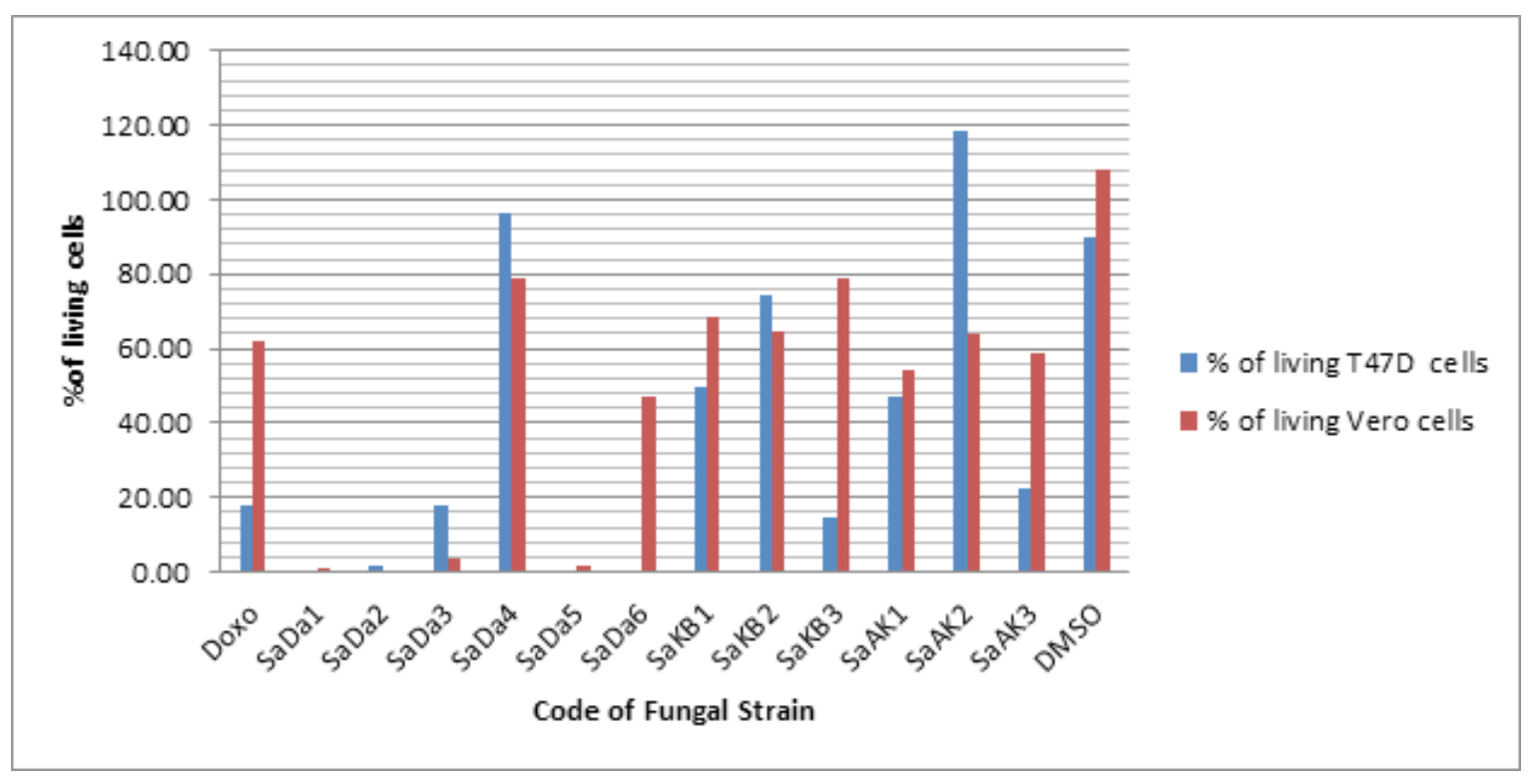

Fig. 1: Cytotoxic activity of endophytic fungi extracts of S. alba SM on T47D and Vero cells.

\section{Molecular Identification of selected fungal extracts}

The three active antibacterial and cytotoxic extracts above were selected for characterization and identification based on its molecular characterization. Based on BLAST results on the NCBI database on the $18 \mathrm{~S}$ sequence ribosomal RNA gene sample of SaKB1, obtained a 100\% homology with Trichoderma koningiopsis TVD fungal-culture $18418 \mathrm{~S}$ ribosomal RNA gene, partial sequence; internal transcribed spacer $1,5.8 \mathrm{~S}$ ribosomal RNA gene, and internal transcribed spacer 2, complete sequence; and $28 \mathrm{~S}$ ribosomal RNA gene, partial sequence.

Based on BLAST results on the NCBI database on the $18 \mathrm{~S}$ sequence ribosomal RNA gene sample of SaAK3 obtained a 99\% homology with RNA gene of Aspergillus sydowii strain FJAT-30991 18S ribosomal RNA gene, partial sequence; internal transcribed spacer 1, 5.8S ribosomal RNA gene, and internal transcribed spacer 2, complete sequence; and 28S ribosomal RNA gene, partial sequence.

Based on BLAST results on the NCBI database on the $18 \mathrm{~S}$ sequence ribosomal RNA gene sample of SaKB4 obtained a 99\% homology with Trichoderma lixii isolate F481RSF1518S ribosomal RNA gene, partial sequence; internal transcribed spacer 1, 5.8S ribosomal RNA gene, and internal transcribed spacer 2, complete sequence; and 28S ribosomal RNA gene, partial sequence.

Based on research reported that on each plant can be found one or more types of endophytic microbes (Strobel and Daisy, 2003). The endophytic microbe has grown to colonize the stem, root, petiole, the leaf segments, flowering weeds, fruit, buds and seeds (Stępniewska and Kuzniar, 2013). According to Dudeja and Giri, 2014, the population of endophyte on plant species varies widely and depends on the various components, such as the host species, stage of development of the host, inoculum density and environmental conditions.

The endophytic fungi have been known to produce some potential antibiotic and anticancer drugs. Fungal cytotoxic to numerous cell lines metabolite such as Penicillenols, was isolated from Penicillium sp. The most effective and successful anticancer drug extracted from endophytic fungi to date is Taxol, isolated from Taxomyces andreanae. Another compound such as Clavatol (Torreya mairei), sordaricin (Fusarium sp.), jesterone (Pestalotiopsis jesteri), and javanicin (Chloridium sp.) are all known to possess strong antibacterial and antifungal properties against numerous foodborne infectious agents (Jalgaonwala et al., 2011).

Our research on endophytic fungi isolated from leaves, roots, and bark of $S$. alba was succesful to select 3 species of potential fungi producing antibacterial and cytotoxic compounds; Trichoderma koningiopsis, Trichoderma lixii and Aspergillus sydowii.

The fungal genus Trichoderma (Ascomycetes, Hyprocreales) was reported to have an ability in producing different metabolites depended on ecological factors, and that strains showed varying effects on pathogens. Marine fungus of Trichoderma species is reportedly significant in silico anti-cancer activity against human skin and breast cancer protein. Marine fungus of Trichoderma harzianum isolated from the sedimentary coast of Arab gulf in Fawregion in southern Iraq has the potential for antibacterial and antifungal activities (Jafar et al., 2016). The koninginins N-Q, four new fungal polyketides, and four known analogs were isolated from the endophytic fungus Trichoderma koningiopsis YIM PH30002 from Panax notoginseng (Liu et al., 2016).

The fungal genus of Aspergillus is well known as a potential source of bioactive compounds in the pharmaceutical field. Aspergifuranone and isocoumarin derivatives were produced by mangrove endophytic fungus Aspergillus sp. 16-5B. The fungus was isolated from the leaves of Sonneratia apetala from Dongzhaigang Mangrove National Nature Reserve in Hainan Island, China. All isolated compounds were evaluated for their $\alpha$-glycosidase inhibitory activities, and Aspergifuranone 
showed significant inhibitory activity with an $\mathrm{IC}_{50}$ value of $9.05 \pm 0.60 \mu \mathrm{M}$ (Liu et al., 2015). A. sydowii has been reported mainly from marine sources and produce some biologically active compounds. One new alkaloid, named as acremolin C, was isolated from static culture of Antarctic fungus, Aspergillus sydowii SP-1, and displayed weak inhibition activities against MRSA and MRSE (Li et al., 2017).

\section{CONCLUSION}

The results obtained indicate that endophytic fungi derived from mangrove Sonneratia alba Sm are an important source of antibiotic and anticancer compounds. Three selected endophytic fungi Trichoderma koningiopsis, Aspergillus sydowii and Trichoderma lixii have been isolated from the root and bark of mangrove. The results of this study indicate that endophytic fungi need to be explored further and continuous research should be done to purify and identify the bioactive compounds as well as optimization of the fermentation process.

\section{CONFLICT OF INTERESTS}

The authors declare that no conflict of interest is associated with this work.

\section{ACKNOWLEDGEMENT}

We gratefully acknowledged to Andalas University, Padang, Indonesia, for the project Grant of "Hibah Klaster Riset Guru Besar”, No. 11/UN.16.17/PP.HGB/LPPM/2017.

\section{REFERENCES}

Alfaro AP, Boyman P. Hidden fungi, emergent properties: endophytes and microbiomes. Annu. Rev. Phytopathol. 2011; 49:291-315.

Bauer AW, Kirby WMM, Sherris JC, Turck M. Antibiotic susceptibility testing by a standardized single disk method. American Journal of Clinical Pathology. 1966; 36:493-496.

Dudeja SS, and Giri R. Beneficial properties, colonization, establishment and molecular diversity of endophytic bacteria in legume and non-legume. Afr. J. Microbiol. Res. 2014; 8, 1562-1572. doi: 10.5897/ AJMR2013.6541.

Handayani D, Rivai H, Hutabarat M, Rasyid R. Antibacterial Activity of Endophytic Fungi Isolated from Mangrove Plant Sonneratia griffithii Kurz. J App Pharm Sci. 2017; 7 (04): 209-212.

Handayani D, and Artasasta MA. Antibacterial and cytotoxic activities screening of symbiotic fungi extracts isolated from marine sponge Neopetrosia chaliniformis AR-01. J App Pharm Sci, 2017; 7 (05): 066-069.

Handayani D, and Aminah I. Antibacterial and cytotoxic activities of ethyl acetate extract of symbiotic fungi from West Sumatra marine sponge Acanthrongylophora ingens. J App Pharm Sci, 2017; 7(02): 237-240.

Handayani D, Ornando R and Rustini, Antimicrobial Activity
Screening of Symbiotic Fungi from Marine Sponge Petrosia nigrans collected from South Coast of West Sumatra Indonesia. International Journal of Pharmacognosy and Phytochemical research, 2016; 8(4): 623625 .

Handayani D, Ahdinur, RF, and Rustini R. Antimicrobial Activity of Endophytic Fungi from Marine Sponge Haliclona fascigera. Journal of App Pharm Sci, 2015; 5(10): 154-156.

Jafar FN, Al-Kamil ML and Al-Salihi NJ. Isolation and Identification of Bioactive Compound from a New Strain of Trichoderma Harzianum and Estimate Its Bioactivity. Journal of Chemical, Biological, and Physical Sciences. 2016; 6(2): 459-468.

Jalgaonwala RE, Mohite BV, and Mahajan RT. Natural products from plant associated endophytic fungi. J. Microbiol. Biotechnol. Res. $2011 ; 1,21-32$

Kjer J, Debbab A, Aly AH, Proksch P. Methods for isolation of marine-derived endophytic fungi and their bioactive secondary products. Nature Protocols, 2010; 5(3): 479-490.

Latha R, Mitra S. Mangrove fungi in India. Current Science. 1998; 86:1586-1587

Liu, K, Yang, YB, Chen, JL, Miao, CP, Wang, Q, Zhou, H, Chen, YW, Li, YQ, Ding, ZT, Zhao, LX Koninginins N-Q, Polyketides from the Endophytic Fungus Trichoderma koningiopsis Harbored in Panax notoginseng, Nat. Prod. Bioprospect. 2016; 6:49-55

Liu, Y, Chen, S, Liu, Z, Lu, Y, Xia, G, Liu, H, He, L, She, Z. Bioactive metabolites from mangrove endophytic fungus Aspergillus sp. 16-5B. Mar. Drugs. 2015; 13: 3091-3102.

Li WT, Luo D, Huang JN, Wang LL, Zhang FG, Xi T, Liao, JM and $\mathrm{Lu}$ YY. Antibacterial constituents from Antarctic fungus, Aspergillus sydowii SP-1, Natural Product Research, 2017 Jun 12:1-6-7, DOI: 10.1080/14786419.2017.1335730

Permanasari P, Hertiani T, Yuswanto A. Immunomodulatory Effect of Massoia Bark Extract and The Cytotoxicity Activity Against Fibroblast and Vero Cells in Vitro. International Journal of Pharmaceutical and Clinical Research, 2016; 8(5) Suppl:326-330.

Stępniewska Z, and Kuzniar A. Endophytic microorganismspromising applications in bioremediation of greenhouse gases. Appl. Microbiol. Biotechnol. 2013; 97, 9589-9596. doi: 10.1007/s00253-013$5235-9$

Strobel GA, Daisy B. Bioprospecting for microbial endophytes and their natural products. Microbiology and Molecular Biology Reviews. 2003; 67 (4):491-502.

White TJ, Bruns T, Lee S and Taylor J. Amplification and direct sequencing of fungal ribosomal RNA Genes for phylogenetics. In PCR Protocols. 1990; 315-322.

How to cite this article:

Handayani D, Rivai H, Mulyana R, Suharti N, Rasyid R, Hertiani T. Antimicrobial and Cytotoxic Activities of Endophytic Fungi Isolated from Mangrove Plant Sonneratia alba Sm. J App Pharm Sci, 2018; 8(02): 049-053. 